\title{
Larvicidal and Adult Mosquito Attractant Activity of Auricularia auricula-judae Mushroom Extract on Aedes aegypti (L.) and Culex sitiens Wiedemann
}

\author{
Tanawat Chaiphongpachara ${ }^{{ }^{*}}$, Kantima Sumchung ${ }^{2}$, Kitthisak Khlaeo Chansukh $^{3}$ \\ ${ }^{1}$ College of Allied Health Sciences, Suan Sunandha Rajabhat University, Thailand. \\ ${ }^{2}$ Bachelor of Public Health, College of Allied Health Sciences, Suan Sunandha Rajabhat University, Thailand. \\ ${ }^{3}$ Department of Applied Thai Traditional Medicine, College of Allied Health Sciences, Suan Sunandha Rajabhat University, Thailand.
}

\begin{tabular}{l}
\hline ARTICLE INFO \\
\hline Article history: \\
Received on: $25 / 05 / 2018$ \\
Accepted on: $11 / 07 / 2018$ \\
Available online: $31 / 08 / 2018$ \\
\hline Key words: \\
Auricularia auricula-judae, \\
Aedes aegypti, Culex sitiens, \\
larvicidal effect, mosquito \\
attractant effect.
\end{tabular}

\begin{tabular}{l}
\hline ABSTRACT \\
Mosquitoes are small insects that are major vectors for the transmission of many diseases to humans, including \\
malaria, dengue fever, yellow fever, lymphatic filariasis, and Japanese encephalitis. These diseases are significant \\
public health problems worldwide, especially in tropical and sub-tropical countries. In this study, we evaluated the \\
effect of Auricularia auricula-judae mushroom extract on larvicidal and adult mosquito attractant activity of important \\
vectors, including Aedes aegypti $(\mathrm{L}$.) and Culex sitiens Wiedemann. Five concentrations of extract at $120,12,1.2,0.12$ \\
and $0.012 \mathrm{mg} / \mathrm{L}$ for the larvicidal assay were used, while concentrations for the attraction of adult mosquitoes were \\
$10^{-4} \mathrm{~g} / \mathrm{mL}, 10^{-5} \mathrm{~g} / \mathrm{mL}$ and $10^{-6} \mathrm{~g} / \mathrm{mL}$. The results of the larvicidal activity assay with the $A$. auricula-judae extract on \\
both species investigated herein of mosquitoes did not affect $A e$. aegypti larvae, though with $C x$. sitiens mosquitoes, \\
the mushroom extract slightly eliminated larvae at all concentrations. The results with the $A$. auricula-judae extract on \\
adult mosquito attractant activity at three concentrations showed at $10^{-5} \mathrm{~g} / \mathrm{mL}$, the most attraction took place followed \\
by $10^{-6} \mathrm{~g} / \mathrm{mL}$ and $10^{-4} \mathrm{~g} / \mathrm{mL}$, respectively ( $11.66 \pm 0.57$ vs. $7.00 \pm 1.00,11.33 \pm 0.57$ vs. $6.66 \pm 0.57$, and $9.33 \pm 0.57$ \\
vs. $6.00 \pm 1.00 \mathrm{mosquitoes,} \mathrm{respectively).} \mathrm{However,} \mathrm{statistical} \mathrm{difference} \mathrm{comparison} \mathrm{of} \mathrm{the} \mathrm{number} \mathrm{of} \mathrm{mosquitoes}$ \\
attracted between A. auricula-judae extract and octenol were found to be different at all concentrations $(p>0.05)$. \\
Although the performance of $A$. auricula-judae extract is not equal to that of octanol, it was effective in attracting \\
more than half of Ae. aegypti mosquitoes as dengue vector $(58.33 \%)$.
\end{tabular}

\section{INTRODUCTION}

Mosquitoes are small insects that are major vectors for the transmission of many diseases to humans, including malaria, dengue fever, yellow fever, lymphatic filariasis, and Japanese encephalitis (Service, 2008; Damapong et al.,2016). These diseases are significant public health problems worldwide, especially in tropical and sub-tropical countries (Chaiphongpachara et al.,2017). WHO estimates that every year, more than one million people die and nearly half of the world's population inhabit high-risk areas

\footnotetext{
${ }^{*}$ Corresponding Author

Mr. Tanawat Chaiphongpachara, College of Allied Health Science, Suan Sunandha Rajabhat University, Samut Songkhram 75000, Thailand. E-mail:tanawat.ch@ssru.ac.th
}

for mosquito-borne diseases (World Health Organization, 2014; World Health Organization, 2016). In 2014, dengue fever, which is mainly transmitted by Aedes aegypti, has increased 30-fold over the past 30 years, with more than 2.5 billion people in more than 100 countries now being at risk of infection and increasing numbers of countries reporting outbreaks of this disease (World Health Organization, 2014). These diseases are also a major problem in Thailand, with many people being infected each year, particularly with dengue fever. According to the Ministry of Public Health of Thailand, the number of patients with these diseases in 2017 was approximately 65,000 cases (Ministry of Public Health, 2014), indicating that these diseases are considerable health issues and should be resolved urgently.

The control of mosquito-borne diseases decreases the natural mosquito population (Roiz et al., 2012). There are two ways 
to control vectors reducing the number of larvae and compromising the adult stage of mosquitoes. Temephos is an organophosphate larvicide that is a popular and widely used chemical product which effectively controls larval stage especially Aedes aegypti, and it is not toxic to humans or animals (Chaiphongpachara et al., 2017). However, there are currently reports of resistance of mosquitoes to this chemical occurring in many areas around the globe, including Thailand, owing to the employment of this chemical for a long time (Jirakanjanakit et al., 2007). This is a major obstacle that has created difficulties in controlling the mosquito population.

Mosquito traps are another tool with which to reduce adult mosquito populations, especially Culex and Anopheles mosquitoes (Hock, 2004). Nowadays, there is the use of smell for optimization based on female mosquitoes requiring a blood meal to provide protein for egg production. Octenol (1-octen-3-ol) is a volatile organic compound found in the sweat and breath of humans that attracts mosquitoes (Takken and Kline, 1989). Although octenol attracts mosquitoes, it is quite expensive; therefore it is not popular in Thailand despite its high performance. Octenol is found in mushrooms and it is reportedly toxic to insects (Thongwat et al., 2015; Inamdar and Bennett, 2014).

From all mentioned to this point, we selected Auricularia auricula-judae mushrooms as an edible and commercially available mushroom species grown in Thailand. The aim of this study was to assess larvicidal and adult mosquito attractant activity of this mushroom extract with respect to Aedes aegypti (L.) as a dengue vector and Culex sitiens Wiedemann as a filariasis and Japanese encephalitis vector (predominantly in costal habitats) (Chaiphongpachara and Sumruayphol, 2017). The results from this research revealed the ability of $A$. auricula-judae mushrooms to be utilized in controlling mosquitoes, leading to the creation of new additional new products.

\section{METHODS}

\section{Collection of $A$. auricula-judae mushroom}

A. auricula-judae mushrooms were collected from the Talat Thai market, Klong Luang Distinct, Pathum Thani province in Thailand (14² $\left.4^{\prime} 54.51^{\prime \prime} \mathrm{N} 100^{\circ} 37^{\prime} 53.06^{\prime \prime E}\right)$ (Figure 1) during September 2016. Afterwards, mushroom samples were brought to the College of Allied Health Sciences, Suan Sunandha University, Samut Songkhram province and identified morphologically by characteristics through making use of the mushroom taxonomic keys (Largent and Thiers, 1977; Largent et al., 1977; Stuntz, 1977; Largent, 1986; Largent and Baroni, 1988).

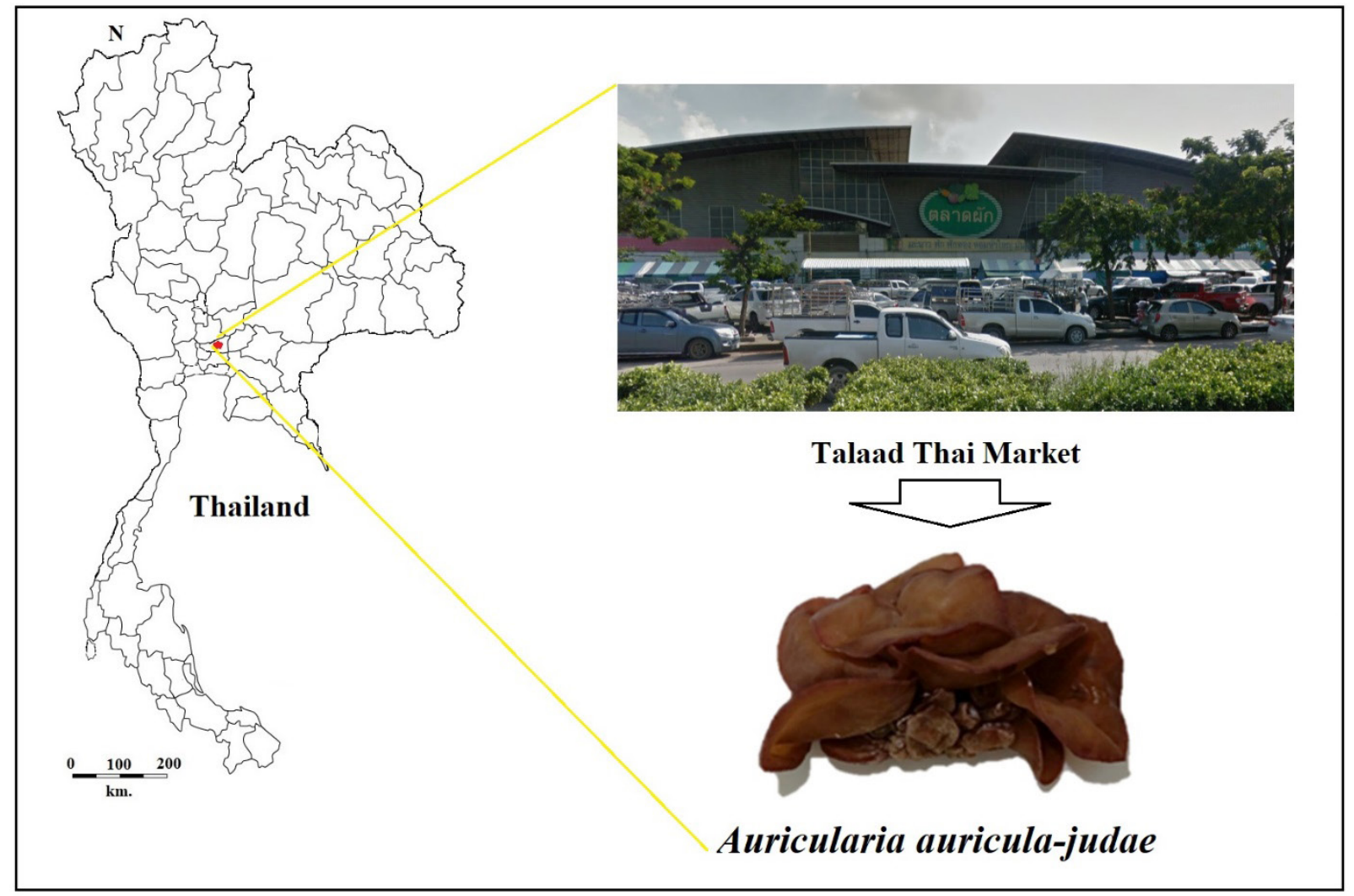

Fig. 1: Location of the collection site in Thailand.

\section{Preparation of mushroom extract}

A. auricula-judae samples were dried in the shade at environmental temperatures of approximately $37^{\circ} \mathrm{C}$, ground to coarse powder and fermented with ethanol $95 \%$ at room temperature for 48 hours. The mushroom extract was filtrated by a Buchner funnel with Whatman number 1 filter paper and evaporated, whereas the water extract was lyophilized to dryness by a rotary evaporator. The yields of crude extract were weighed, 
recorded, dissolved in methanol for adult mosquito bioassay and distilled water for larvicidal bioassay and stored at $-20^{\circ} \mathrm{C}$ before mosquito testing in the laboratory.

\section{Mosquito rearing}

In this work, we assessed the effect of $A$. auricula-judae extract against Ae. aegypti and $C x$. sitiens. Ae. aegypti Bora Bora strain (WHO-susceptible strain) supported by the Faculty of Tropical Medicine, Mahidol University. $C x$. sitiens were collected from the coastal field of Samut Songkhram province, which is 200 meters away from the sea $\left(13^{\circ} 23^{\prime} 31.57^{\prime \prime} \mathrm{N} 100^{\circ} 1^{\prime} 59.36^{\prime \prime} \mathrm{E}\right)$ by a standard mosquito dipper in a water source with a salinity level of more than 0.05 ppt. We then added Ae. aegypti eggs and $C x$. sitiens larvae to a tray containing filtered water $(25 \times 30 \times 5$ $\mathrm{cm}$ ) by separating each species per tray at $25 \pm 2^{\circ} \mathrm{C}$ with a $10: 14$ light:dark photoperiod and $0.1 \mathrm{~g} / \mathrm{mL}$ dag food daily. During the pupae stage, they were transferred to a cage $(30 \times 30 \times 30 \mathrm{~cm})$ to facilitate adult mosquito emergence.

\section{Bioassay for the larvicidal activity of $A$. auricula-judae extract}

A larvicidal bioassay of this mushroom extract is recommended according to WHO (WHO, 2016). Five concentrations of extract at $120,12,1.2,0.12$ and $0.012 \mathrm{mg} / \mathrm{L}$ were used. Filtered water containing each substance concentration was poured into a six-ounce glass and 20 late third-instar larvae or early forth-instar larvae were added. After 24 hours, exposed dead larvae were counted and recorded for three replications. For the control group, we added extraction solvent into the testing glass. Octenol (1-Octanol EMPLURA ${ }^{\circledR}$ from Merck KGaA Company, Darmstadt, Germany) was used as a comparison group in all concentrations for testing against larvae and adult mosquitoes.

\section{Bioassay for adult mosquito attractant activity of $A$. auricula- judae extract}

Three concentrations of mushroom extract at $10^{-4} \mathrm{~g} /$ $\mathrm{mL}, 10^{-5} \mathrm{~g} / \mathrm{mL}$ and $10^{-6} \mathrm{~g} / \mathrm{mL}$ were employed for determining the attraction of adult mosquitoes. We conducted this bioassay with a modified Y-tube, according to Geier (Geier and Boeckh, 1999), using 20 mosquitoes per concentration performed in four replicates. This bioassay began with the release of female mosquitoes into the Y-tube, which has two intersections within the tube; the left side is where the mushroom extract was added, while the right side of the tube was where the extraction solvent was added. When mosquitoes flew to the end of the tube, we counted and recorded the results.

\section{Statistical analyses}

The numbers of dead larvae and numbers of mosquito attracted were presented using the mean $( \pm$ standard deviation [S.D.]). Comparative analysis of the number of mosquitoes attracted between $A$. auricula-judae extract and oetenol was performed at all concentrations with a t-test with $95 \%$ confidence intervals $(p<0.05)$.

\section{RESULTS AND DISCUSSION}

In the work presented here, we assessed the effect larvicidal and adult mosquito attractant activity of $A$. auricula- judae mushroom extracts on Ae. aegypti and Cx. sitiens.

\section{Efficacy of $A$. auricula-judae extract for larvicidal activity}

The results surrounding the larvicidal effect of the mushroom against both mosquito species showed that $A$. auriculajadae extract did not affect larvae of Ae. aegypti and only very few of the $C x$. sitiens larvae died at all concentrations (Table 1). While octenol, the highest concentration at $120 \mathrm{mg} / \mathrm{L}$ showed a profound ability to affect $C x$ sitiens $(19.67 \pm 0.58)$ but less with Ae. aegypti $(9.33 \pm 4.93)$. In the control group, with no $A$. auricula-judae extract, Ae. aegypti did not die but we did observe a number of deaths for $C x$. sitiens $(0.33 \pm 0.58)$. These results are consistent with Thongwat et al. (Thongwat et al., 2015), who screened 143 species of mushroom against Ae. aegypti larvae and found larvicidal activity in only Thaeogyroporus porentosus, Xylaria nigripes, Chlorophyllum spp. and Steccherinum spp., along with two unidentified species. In spite of this, it is reported that octenol can be used to eliminate small insects (Inamdar and Bennett, 2014). This is consistent with the results of octenol in this experiment that the maximum concentration $(120 \mathrm{mg} / \mathrm{L})$ can kill almost all larvae of $C x$. sitiens $(98.35 \%)$ and about half of all Ae. aegypti larvae (46.65\%). Temephos has been used to control and is the most popular, highest performance and cheapest. Criteria for susceptibility to larvae are set at $0.012 \mathrm{mg} / \mathrm{L}$ temephos as recommended by the World Health Organization standard. The results of octenol substance compared to the criteria of temephos were that it had the ability to eliminate mosquitoes slightly (1.65\% of Ae aegypti and $25 \%$ of Cx. sitiens). Therefore, both $A$. auricula-judae extract and octenol are not suitable for use in the field because they are less powerful.

Table 1: Mean dead numbers of the larvae of Ae. aegypti and Cx. sitiens.

\begin{tabular}{cccccc}
\hline \multirow{2}{*}{$\begin{array}{c}\text { Concentrations } \\
(\mathrm{mg} / \mathrm{L})\end{array}$} & $\mathrm{n}$ & \multicolumn{2}{c}{ A. auricula-judae } & \multicolumn{2}{c}{ Octenol } \\
\cline { 3 - 6 } & 20 & ND & $2.00 \pm 1.00$ & $9.33 \pm 4.93$ & $19.67 \pm 0.58$ \\
120 & 20 & ND & $3.67 \pm 2.52$ & $0.33 \pm 0.58$ & $9.67 \pm 3.06$ \\
12 & 20 & ND & $2.67 \pm 1.53$ & ND & $6.00 \pm 2.00$ \\
1.2 & 20 & ND & $2.67 \pm 3.21$ & $1.00 \pm 1.00$ & $5.00 \pm 2.65$ \\
0.12 & 20 & ND & $2.00 \pm 1.73$ & $0.33 \pm 0.58$ & $5.00 \pm 2.65$ \\
0.012 & 20 & ND & $0.33 \pm 0.58$ & ND & ND \\
\hline Control group & 20 . & & & &
\end{tabular}

$\mathrm{ND}=$ No deaths of mosquito larvae

\section{Efficacy of $\boldsymbol{A}$. auricula-judae extract for mosquito attraction}

The effects of $A$. auricula-judae crude extract attracting adult $A e$. aegypti and $C x$ sitiens at three levels of concentration showed that $10^{-5} \mathrm{~g} / \mathrm{mL}$ attracted the most of both species of mosquitoes followed by $10^{-6} \mathrm{~g} / \mathrm{mL}$ and $10^{-4} \mathrm{~g} / \mathrm{mL}$, respectively $(11.66 \pm 0.57$ vs. $7.00 \pm 1.00,11.33 \pm 0.57$ vs. $6.66 \pm 0.57$ and $9.33 \pm 0.57$ vs. $6.00 \pm 1.00$ mosquitoes, respectively) (Table 2). While the effects of this extract attracted female Ae. aegypti more so than $C x$. sitiens at all concentrations.

Octenol's scent powerfully attracts female mosquitoes, and several studies have reported octenol being contained in mushrooms (Dijkstra, 1976). The results of the assay with $A$. auricula-judae extract for adult mosquito attractant activity 
demonstrated the ability to attract adult mosquitoes by more than $50 \%(58.33 \%)$ of Ae. aegypti at $10^{-5} \mathrm{~g} / \mathrm{mL}$ concentration, while $C x$. sitiens was less attracted less Ae. aegypti at all concentrations. These findings are in line with previous research that found this concentration could best attract mosquitoes, especially Aedes mosquitoes (Cilek et al., 2011). However, a comparison of the number of mosquitoes attracted to $A$. auricula-judae extract and oetenol were different at all concentrations $(p>0.05)$ (Figure 2).
Table 2: Mean number of adult Ae. aegypti and Cx. sitiens responses.

\begin{tabular}{cccccc}
\hline \multirow{2}{*}{$\begin{array}{c}\text { Concentrations } \\
(\mathrm{g} / \mathrm{mL})\end{array}$} & $\mathbf{n}$ & \multicolumn{2}{c}{ A. auricula-judae } & \multicolumn{2}{c}{ Octenol } \\
\cline { 3 - 6 } & & Ae. aegypti & Cx. sitiens & Ae. aegypti & Cx. sitiens \\
\hline $10^{-4}$ & 20 & $9.33 \pm 0.57$ & $6.00 \pm 1.00$ & $15.33 \pm 0.57$ & $11.00 \pm 0.33$ \\
$10^{-5}$ & 20 & $11.66 \pm 0.57$ & $7.00 \pm 1.00$ & $16.33 \pm 0.57$ & $12.66 \pm 1.15$ \\
$10^{-6}$ & 20 & $11.33 \pm 0.57$ & $6.66 \pm 0.57$ & $16.00 \pm 0.00$ & $11.66 \pm 0.57$ \\
\hline
\end{tabular}

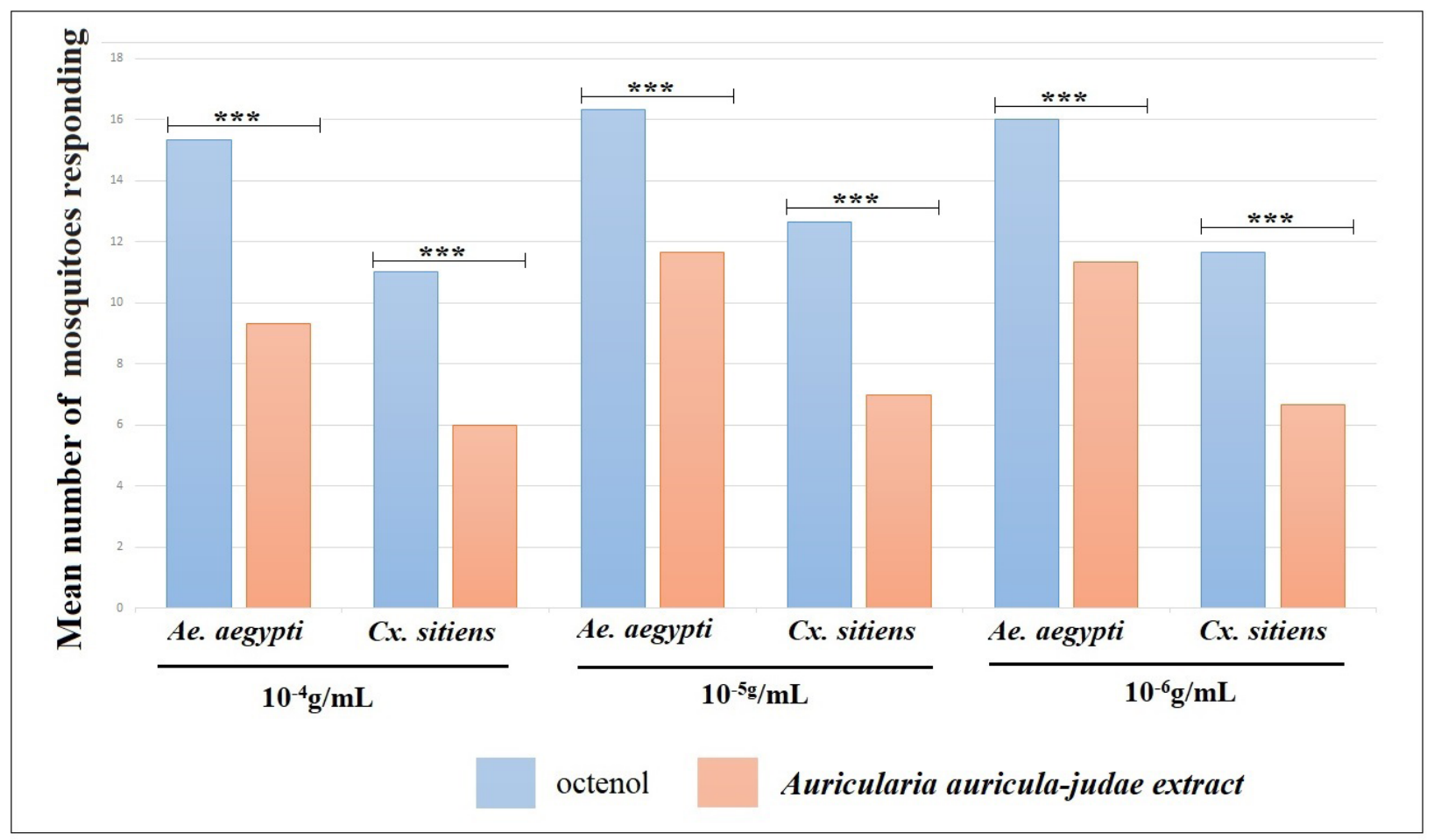

Fig. 2: Comparative analysis of the mean number of mosquitoes responding to A. auricula-judae extract and octenol.*** $=$ Statistical difference is significant at the 0.05 level (two-tailed).

\section{CONCLUSION}

Although A. auricula-judae extract is not equal to octenol in terms of its ability to kill larvae or attract adult females, it is possible to develop a higher efficacy, such as incorporating other substances to attract mosquitoes, especially dengue vector according to our results, revealing a capacity to attract more than half of all Ae. aegypti mosquitoes. With this, A. auriculajudae extract has the compelling features of being inexpensive and eco-friendly and serves as a robust option for increasing the effectiveness of controlling mosquito-borne diseases.

\section{ACKNOWLEDGMENTS}

We would like to acknowledge and thank the College of Allied Health Science, Suan Sunandha Rajabhat University, Thailand, for their kind support of our research.

\section{CONFLICT OF INTEREST}

There are no conflicts of interest related to this research.

\section{REFERENCES}

Ministry of Public Health, Thailand. 2014. http://www.thaivbd. org/n/home; Accessed [15 Dec. 2017].

Chaiphongpachara T, Sumruayphol S. Species diversity and distribution of mosquito vectors in coastal habitats of Samut Songkhram province. Thailand. Trop. Biomed, 2017; 34:524-532.

Chaiphongpachara T, Moolrat L. Insecticide resistance of temephos on Aedes aegypti as dengue vector in Samut Songkhram, Thailand. Ann. Trop. Med. Public Health, 2017; 10:1439-1442.

Chaiphongpachara T, kaebkhunthod J, Laojun S, Kunphichayadecha C, Saisanan Na Ayudhaya W, Wassanasompong W. Insecticide susceptibility of Aedes aegypti larvae to Bacillus thuringiensis israelensis and juvenile hormone in dengue epidemic areas of Samutsongkhram. Thailand. Int. J. Geomate, 2017; 12:53-60.

Cilek JE, Ikediobi CO, Hallmon CF, Johnson R, Onyeozili EN, Farah SM, Mazu T, Latinwo LM, Ayuk-Takem L, Berniers UR. Semi-field evaluation of several novel alkenol analogs of 1-octen-3-ol as attractants to adult Aedes albopictus and Culex quinquefasciatus. J. Am. Mosq. Control Assoc, 2011; 27:256-262.

Damapong P, Damapong P, Jumparwai S, Kaen K. Model development for outbreak of dengue fever. Int J Geomate, 2016; 11:27772781.

Dijkstra FY. Studies on Mushroom Flavours 3. Some compounds in Fresh,Canned and Dried Edible Mushrooms. Zeitschrift fuer Leb. -Untersuchung und-forsch, 1976; 160:401-405.

Geier M, Boeckh J. A new Y-tube olfactometer for mosquitoes 
to measure the attractiveness of host odours. Entomol. Exp. Appl, 1999; 92:9-19.

Hock JW. CDC Miniature Light Trap. Expert. Insect Sampl. 2004.

Largent DL. How to identify mushrooms to genus I: macroscopic features. Eureka: Eureka Printing. Mad River Press. 1986.

Largent DL, Baroni TJ. How to identify mushrooms to genus VI: modern genera. Eureka: Eureka Printing. Mad River Press. 1988.

Largent DL, Johnson D, Watling R. How to identify mushrooms to genus III: microscopic features. Eureka: Eureka Printing. Mad River Press. 1977.

Largent DL, Thiers HD. How to identify mushrooms to genus II: field identification of genera. Eureka: Eureka Printing. 1977. Published by Mad River, Eureka, CA (1977).

Inamdar AA, Bennett JW. A common fungal volatile organic compound induces a nitric oxide mediated inflammatory response in Drosophila melanogaster. Sci. Rep. 2014; 4:1-9.

Jirakanjanakit N, Saengtharatip S, Rongnoparut P, Duchon S, Bellec C, Yoksan S. Trend of Temephos Resistance in Aedes (Stegomyia) Mosquitoes in Thailand During 2003-2005. Environ. Entomol. 2007; 36:506-511.

Roiz D, Roussel M, Munõz J, Ruiz S, Soriguer R, Figuerola J. Efficacy of mosquito traps for collecting potential west nile mosquito vectors in a natural mediterranean wetland. Am. J. Trop. Med. Hyg, 2012; $86: 642-648$

Service M. Medical entomology for students, fourth edition,
Medical Entomology for Students. 2008.

Stuntz DE. How to identify mushrooms to genus IV: key to families and genera. Eureka: Eureka Printing. Mad River Press. 1977.

Takken W, Kline DL. Carbon dioxide and 1-octen-3-ol as mosquito attractants. J. Am. Mosq. Control Assoc, 1989; 5:311-316.

Thongwat D, Pimolsri U, Somboon P. Screening for mosquito larvicidal activity of thai mushroom extracts with special reference to Steccherinum sp against Aedes aegypti (L.) (Diptera: Culicidae). Southeast Asian J. Trop. Med. Public Health, 2015; 46:586-595.

World Health Organization, Monitoring and managing insecticide resistance in Aedes mosquito populations Interim guidance for entomologists. WHO. 2016.

World Health Organization, Mosquito born diseases. WHO. 2016, http://www.who.int/whr/1996/media_centre/executive_summary1/ en/index 9. html.

World Health Organization, Vector-borne diseases. 2014. http:// www.who.int/kobe_centre/mediacentre/vbdfactsheet.pdf; Accessed [07 May 2018].

How to cite this article:

Chaiphongpachara T, Sumchung K, Chansukh KK. Larvicidal and Adult Mosquito Attractant Activity of Auricularia auriculajudae Mushroom Extract on Aedes aegypti (L.) and Culex sitiens Wiedemann. J App Pharm Sci, 2018; 8(08): 021-025. 